\title{
Altered Brain Serotonin Transporter and Associated Glucose Metabolism in Alzheimer Disease
}

\author{
Yasuomi Ouchi ${ }^{1,2}$, Etsuji Yoshikawa ${ }^{3}$, Masami Futatsubashi ${ }^{3}$, Shunsuke Yagi ${ }^{1}$, Takatoshi Ueki ${ }^{4}$, \\ and Kazuhiko Nakamura ${ }^{5}$

\begin{abstract}
${ }^{I}$ Molecular Imaging Frontier Research Center, Hamamatsu University School of Medicine, Higashi-ku, Hamamatsu, Japan;
${ }^{2}$ Positron Medical Center, Hamamatsu Medical Center, Hamakita-ku, Hamamatsu, Japan; ${ }^{3}$ Central Research Laboratory,

Hamamatsu Photonics K.K., Hamakita-ku, Hamamatsu, Japan; ${ }^{4}$ Department of Neuroanatomy, Hamamatsu University School of Medicine, Higashi-ku, Hamamatsu, Japan; and ${ }^{5}$ Department of Psychiatry, Hamamatsu University School of Medicine, Higashi-ku,

Hamamatsu, Japan
\end{abstract}

Whether preclinical depression is one of the pathophysiologic features of Alzheimer disease (AD) has been under debate. In vivo molecular imaging helps clarify this kind of issue. Here, we examined in vivo changes in the brain serotoninergic system and glucose metabolism by scanning early- to moderate-stage $A D$ patients with and without depression using PET with a radiotracer for the serotonin transporter, ${ }^{11} \mathrm{C}-3-$ amino-4-(2dimethylaminomethylphenylsulfanyl) benzonitrile (DASB), and a metabolic marker, ${ }^{18} \mathrm{~F}-\mathrm{FDG}$. Methods: Fifteen AD patients ( 8 nondepressed and 7 depressed) and 10 healthy subjects participated. All participants underwent 3-dimensional MRI and quantitative ${ }^{11} \mathrm{C}$-DASB PET measurements, followed by ${ }^{18} \mathrm{~F}$-FDG PET scans in the AD group. Region-of-interest analysis was used to examine changes in ${ }^{11} \mathrm{C}$-DASB binding potential estimated quantitatively by the Logan plot method in the serotonergic projection region. In addition, statistical parametric mapping was used to examine whether glucose metabolism in any brain region correlated with levels of ${ }^{11} \mathrm{C}$-DASB binding in the dense serotonergic projection region (striatum) in AD. Results: Psychologic evaluation showed that general cognitive function (Mini-Mental State Examination) was similar between the 2 AD subgroups. Striatal ${ }^{11} \mathrm{C}$-DASB binding was significantly lower in AD patients, irrespective of depression, than in healthy controls $(P<0.05$, corrected), and ${ }^{11} \mathrm{C}$-DASB binding in other dense projection areas decreased significantly in the depressive group, compared with the control group. The ${ }^{11} \mathrm{C}$-DASB binding potential levels in the subcortical serotonergic projection region correlated negatively with depression score (Spearman correlation, $P<0.01$ ) but not with dementia score. Statistical parametric mapping correlation analysis showed that glucose metabolism in the right dorsolateral prefrontal cortex was positively associated with the level of striatal ${ }^{11} \mathrm{C}$-DASB binding in AD. Conclusion: The significant reduction in ${ }^{11} \mathrm{C}$-DASB binding in nondepressed $A D$ patients suggests that presynaptic serotonergic function is altered before the development of psychiatric problems such as depression in $A D$. The depressive $A D$ group showed greater

Received Feb. 9, 2009; revision accepted Apr. 2, 2009.

For correspondence or reprints contact: Yasuomi Ouchi, Laboratory of Human Imaging Research, Molecular Imaging Frontier Research Center, Hamamatsu University School of Medicine, 1-20-1 Handayama, Higashi-

ku, Hamamatsu 431-3192, Japan.

E-mail: ouchi@hama-med.ac.jp

COPYRIGHT () 2009 by the Society of Nuclear Medicine, Inc. and broader reductions in binding, suggesting that a greater loss of serotonergic function relates to more severe psychiatric symptoms in the disease. This serotonergic dysfunction may affect the activity of the right dorsolateral prefrontal cortex, a higher center of cognition and emotion in AD.

Key Words: Alzheimer's disease; serotonin transporter; glucose metabolism; depression; positron emission tomography

J Nucl Med 2009; 50:1260-1266

DOI: 10.2967/jnumed.109.063008

\section{A}

lzheimer disease $(\mathrm{AD})$ is a neurodegenerative disorder with progressive memory and cognitive deterioration followed by or concomitant with psychologic problems such as depression and hallucination, which have a strong negative impact on the course of the disease. The occurrence of these psychologic disturbances has been reported to closely relate to disruption of the serotonergic system (1). Loss of neurons in the serotonergic raphe nuclei (2) and dysfunction of its nerve terminals in the neocortex (3) have been reported in AD. Many lines of evidence support this serotonin (5HT) deficiency theory concerning the psychobehavioral symptomatology of $\mathrm{AD}$, as examined in postmortem (4-6) and pharmacotherapeutic $(7,8)$ studies. A caveat of the postmortem studies is that the findings do not always reflect the antemortem conditions of $\mathrm{AD}$ because of variations of clinical symptoms after a mixture of nootropic and psychiatric drugs administered during the patient's lifetime. In addition, the comorbidity of intrinsic depression in patients with $\mathrm{AD}$ may be a confounding factor in a study of in vivo serotonergic changes in AD. In vivo studies using PET so far have focused on 5HT receptors in the limbic brain region in association with mnemonic cognitive impairment in $\mathrm{AD}$ (9-11). Thus, the alterations in presynaptic 5HT function relative to psychologic and behavioral problems in $\mathrm{AD}$ with and without depression remain to be investigated. 
The serotonergic projections from the dorsal raphe nucleus are dense in the basal ganglia and thalamus $(12,13)$. The 5HT transporter is a component of 5HT presynaptic neurons and a therapeutic target of selective 5HT reuptake inhibitors, which are presently the first-choice treatment for AD patients with depression (1). Because the 5HT transporter located on the presynaptic 5HT terminal regulates 5HT signaling, levels of ${ }^{11} \mathrm{C}$-3-amino-4-(2-dimethylaminomethylphenylsulfanyl) benzonitrile (DASB) binding in these regions reflect the activity of the presynaptic 5HT neurons chiefly in the dorsal raphe nuclei. A recent postmortem study showed a marked reduction in the binding of 5HT transporter tracer in the prefrontal cortex regardless of the presence of depression in AD (14). This finding suggests that the loss of raphe nuclei neurons and cortical 5HT transporter is one of the pathologic features of $\mathrm{AD}$ at the time of death. In addition, a recent SPECT study on AD with depression showed significantly lower perfusion in the dorsolateral prefrontal cortex (DLPFC) in patients with depressive symptoms than in patients without such symptoms (15). The DLPFC is known as a neural substrate of executive function that is consistently compromised in depression (16). Furthermore, patients with frontal glucose hypometabolism exhibit a faster deterioration of cognitive abilities (17) than do patients with glucose hypometabolism only in the posterior brain. Thus, a combination study of the presynaptic 5HT system and cerebral cortical metabolism is important in elucidating the underlying mechanism for $\mathrm{AD}$ with psychotic deterioration.

For this purpose, we measured 2 biomarkers on the same day in mild- to moderate-stage $\mathrm{AD}$ patients with and without depression to investigate the levels of presynaptic serotonergic function and cortical neuronal activity using PET with ${ }^{11} \mathrm{C}$-DASB, a specific 5HT transporter marker, and ${ }^{18} \mathrm{~F}-\mathrm{FDG}$.

\section{MATERIALS AND METHODS}

\section{Participants}

A total of 15 nootropic- and antipsychotic-naïve patients with $\mathrm{AD}$ (8 men, 7 women; mean age $\pm \mathrm{SD}, 61.3 \pm 5.9 \mathrm{y})$ and 10 age-, sex-, and education-matched healthy control subjects ( 5 men, 5 women; mean age, $55.8 \pm 8.8$ y) participated in the study. The diagnosis of AD was based on the criteria of the National Institute of Neurologic and Communicative Disorders and Stroke and the Alzheimer Disease and Related Disorders Association. The clinical dementia rating in all patients ranged from 1.0 to 1.5 , and no patient had psychiatric disorders before the onset of dementia. The participants were evaluated with the Mini-Mental State Examination, the affect test for emotional cognition (subjects evaluate facial expressions on different cards by choosing appropriate answers from the basic emotions: happiness, sadness, surprise, disgust, anger, fear; the full score $=20)(18)$, and the geriatric depression scale (GDS, maximum $=15$ ) for AD patients $(19)$. AD patients were classified into 2 subgroups (nondepressed and depressed) according to the GDS scores as shown in Table 1. The present study was approved by the local Ethics Committee of the Hamamatsu University School of Medicine, and written informed consent was obtained from all participants themselves. We obtained written approval from the spouses or family members of $\mathrm{AD}$ patients as well.

\section{MRI and PET Procedure}

All participants first underwent 3-dimensional MRI just before the PET measurement. We used a static magnet $(0.3 \mathrm{~T}$ MRP7000AD; Hitachi) with 3-dimensional mode sampling to determine the brain areas for setting the regions of interest (ROIs). The MRI measurements and a mobile PET gantry allowed us to reconstruct PET images parallel to the intercommisural line without reslicing. Using this approach, we were able to allocate ROIs to the target regions of the original PET images (20).

PET was performed as described previously (20) on a highresolution brain SHR12000 tomograph (Hamamatsu Photonics K.K.) having an intrinsic resolution of $2.9 \times 2.9 \times 3.4 \mathrm{~mm}$ in full width at half maximum, 47 slices, and a 163 -mm axial field of view. After head fixation using a thermoplastic face mask and a 10-min transmission scan for attenuation correction, serial scanning $(4 \times 30 \mathrm{~s}, 20 \times 60 \mathrm{~s}$, and $14 \times 300 \mathrm{~s})$ with periodic arterial blood sampling was performed for $92 \mathrm{~min}$ after a slow bolus injection (taking $1 \mathrm{~min}$ ) of a $300-\mathrm{MBq}$ dose of ${ }^{11} \mathrm{C}-\mathrm{DASB}$ with a specific activity of more than $90 \mathrm{GBq} / \mu \mathrm{mol}$. The method was the same as described previously for another 5HT transporter tracer, ${ }^{11} \mathrm{C}-\mathrm{McN} 5652$ (21). After completion of the ${ }^{11} \mathrm{C}$-DASB measurement (after 5 times the half-life of ${ }^{11} \mathrm{C}$ had elapsed), $10 \mathrm{~min}$ of emission data were acquired under resting conditions 50 min after

TABLE 1. Clinical Demographics

\begin{tabular}{|c|c|c|c|}
\hline \multirow[b]{2}{*}{ Category } & \multicolumn{2}{|c|}{ AD (8 men, 7 women) } & \multirow[b]{2}{*}{$\begin{array}{c}\text { Control } \\
\text { (5 men, } 5 \text { women }\end{array}$} \\
\hline & $\begin{array}{l}\text { Nondepressed } \\
\text { (4 men, } 4 \text { women) }\end{array}$ & $\begin{array}{c}\text { Depressed } \\
\text { (4 men, } 3 \text { women) }\end{array}$ & \\
\hline Age $(y)$ & $62.3(6.4)$ & $60.1(5.4)$ & $55.8(8.8)$ \\
\hline Education (y) & $13.6(2.2)$ & $14.8(2.8)$ & $14.0(2.1)$ \\
\hline Disease duration $(\mathrm{y})$ & $2.2(1.5)$ & $1.8(0.9)$ & - \\
\hline Mini-Mental State Examination score & $18.9(3.8)^{\star}$ & $17.4(3.8)^{*}$ & $29.2(0.8)$ \\
\hline Affect test score & $12.7(3.6)^{*}$ & $9.4(3.7)^{\star \dagger}$ & $19.0(1.1)$ \\
\hline GDS score & $1.6(0.8)$ & $8.4(1.1)^{\star+}$ & $0.6(0.7)$ \\
\hline \multicolumn{4}{|l|}{$\begin{array}{l}{ }^{*} P<0.01 \text { (paired } t \text { test) vs. control. } \\
{ }^{\dagger} P<0.01 \text { vs. nondepressed AD group. } \\
\text { Data are mean values. with SD in parent }\end{array}$} \\
\hline
\end{tabular}


injection of $90 \mathrm{MBq}$ of ${ }^{18} \mathrm{~F}-\mathrm{FDG}$, according to a previously described autoradiographic technique (22).

\section{Image Data Analysis}

To determine brain ROIs within the $5 \mathrm{HT}$ projection system, we used original morphologic MRI data instead of using spatially normalized MRI data. Most of the cell bodies are in the raphe nuclei in the midsagittal brain stem, with the largest collection of serotonergic neurons residing in the dorsal and median raphe nuclei of the caudal midbrain (23). The use of original MR images allowed us to demarcate ROIs on the region covering the substantia nigra (one of the 5HT projection area) on the MR image. In addition, multiple semicircular ROIs $\left(\sim 36-120 \mathrm{~mm}^{2}\right)$ were drawn bilaterally over the nucleus accumbens, thalamus, putamen, amygdala, prefrontal (Brodmann area 9) and temporal (Brodmann area 21) cortices, and cerebellum on the MR images in reference to an MRI atlas (24). These ROIs were then transferred onto the corresponding dynamic ${ }^{11} \mathrm{C}$-DASB images with $6.8-\mathrm{mm}$ slice-thickness data, generated after adding 2 consecutive slices using image-processing software (Dr View; Asahi Kasei Co.) on a workstation (Ultraspark 300; SUN Microsystems) (20).

In the ROI analysis, ${ }^{11} \mathrm{C}$-DASB binding was quantified using a 2-tissue-compartment model, in which the cerebellar hemisphere was chosen as a reference region. The binding potential (BP) in each target region was calculated by the formula (target tissue $\mathrm{Vd}) /($ cerebellum $\mathrm{Vd})-1$, where each $\mathrm{Vd}$ (the volume of distribution) was obtained by the Logan graphical method (25). Because the pontine and medullary raphe nuclei send a proportion of 5HT axons into the cerebellum, this region is not an ideal candidate for a 5HT-free region. However, the use of the cerebellum as the reference region is acceptable in the present groups because smaller changes in the 5HT system were reported in the cerebellum (26).

In voxelwise analysis of ${ }^{18} \mathrm{~F}-\mathrm{FDG}$ data, all original PET data were converted into semiquantitative parametric images using a unit of standardized uptake denoting the tracer activity per injected dose normalized to body weight. Correlation analysis by statistical parametric mapping (SPM) was performed to examine neural correlates with the level of ${ }^{11} \mathrm{C}$-DASB binding in the dense 5 HT projection area-putamen in the AD group.

\section{Statistics}

First, right and left values for the ROIs in each region were averaged because no significant difference was observed between the interhemispheric values with the Student $t$ test. Then, the regional ${ }^{11} \mathrm{C}$-DASB BP values were compared among the 3 groups with 1-way ANOVA using a post hoc Student-Newman-Keuls test. Statistical significance was set at $P<0.05$ because post hoc multiple comparisons were performed in the analyses. In addition, the Kendall $\tau$ test was performed to compare the regional ${ }^{11} \mathrm{C}$ DASB BP values with the clinical variables in the AD group. The level of significance for the Kendall $\tau$ test was set at $P<0.01$.

For the voxelwise mapping analysis, SPM software was used (SPM2; Wellcome Department of Cognitive Neurology). The standardized uptake value-based ${ }^{18} \mathrm{~F}-\mathrm{FDG}$ images were then smoothed with an isotropic gaussian kernel of an $8 \times 8 \times 8 \mathrm{~mm}$ filter, as described elsewhere (27). Voxel-based correlation between cerebral ${ }^{18} \mathrm{~F}-\mathrm{FDG}$ uptake and the ${ }^{11} \mathrm{C}$-DASB BP in the dense $5 \mathrm{HT}$ projection area was computed by covariance analysis, using age as a confounding covariate. The statistical threshold was set at $P<0.001$, and $P$ values were left uncorrected.

\section{RESULTS}

Levels of ${ }^{11} \mathrm{C}$-DASB Binding in the 3 Groups

One-way ANOVA showed that the levels of ${ }^{11} \mathrm{C}$-DASB $\mathrm{BP}$ in the dense $5 \mathrm{HT}$ projection regions (midbrain, nucleus accumbens, putamen, and thalamus) of the depressed AD group and the level in the putamen of the nondepressed AD group were significantly lower than those in the control group (Table 2; Fig. 1). ${ }^{11} \mathrm{C}$-DASB BP tended to be reduced in other dense projection areas of the 5HT system (nucleus accumbens, thalamus, and midbrain) in the nondepressed AD group. No significant reduction was found in the cortical areas of the AD group. No significant difference in ${ }^{11} \mathrm{C}$-DASB binding was found between the nondepressed and depressed $\mathrm{AD}$ groups, although the depressed $\mathrm{AD}$ group showed a clear tendency toward lower levels. Representative ${ }^{11} \mathrm{C}$-DASB PET images of subjects in each group are shown in Figure 1.

\section{Correlation Between ${ }^{11} \mathrm{C}$-DASB Binding and Clinical Parameters in AD Group}

As shown in Figure 2A, the levels of ${ }^{11} \mathrm{C}$-DASB BP in all dense 5HT projection regions correlated negatively with GDS scores (midbrain: $r=0.692, P<0.01, \mathrm{f}(\mathrm{x})=-0.057 \mathrm{x}+$ 1.834; putamen: $r=0.72, P<0.005, \mathrm{f}(\mathrm{x})=-0.046 \mathrm{x}+1.683$; thalamus: $r=0.839, P<0.005, \mathrm{f}(\mathrm{x})=-0.046 \mathrm{x}+1.638)$, indicating that lower binding of ${ }^{11} \mathrm{C}$-DASB in the $5 \mathrm{HT}$ system may be related to greater deterioration of the emotional state in AD. Although no significant correlation was found with the scores for dementia (Mini-Mental State Examination, Fig. 2B) or emotional cognition (affect test, Fig. 2C), there was a tendency toward positive correlations between the putaminal ${ }^{11} \mathrm{C}$-DASB BP and the MiniMental State Examination scores and between subcortical ${ }^{11} \mathrm{C}$-DASB BPs and the affect scores.

\section{Neural Correlates of Cerebral Glucose Metabolism with Striatal ${ }^{11} \mathrm{C}$-DASB Binding in AD Group}

SPM correlation analysis showed that glucose metabolism in the right DLPFC and superior frontal gyrus corre-

\begin{tabular}{|c|c|c|c|}
\hline \multirow[b]{2}{*}{ Brain region } & \multicolumn{2}{|c|}{$A D$} & \multirow[b]{2}{*}{ Control } \\
\hline & Nondepressed & Depressed & \\
\hline Midbrain & $1.73(0.32)$ & $1.34(0.15)^{\star}$ & $2.01(0.55)$ \\
\hline $\begin{array}{l}\text { Nucleus } \\
\text { accumbens }\end{array}$ & $1.18(0.21)$ & $1.03(0.55)^{\star}$ & $1.64(0.37)$ \\
\hline Putamen & $1.54(0.12)^{*}$ & $1.27(0.25)^{\star}$ & $2.05(0.50)$ \\
\hline Thalamus & $1.64(0.18)$ & $1.35(0.11)^{\star}$ & $2.00(0.23)$ \\
\hline Amygdala & $1.14(0.32)$ & $0.80(0.31)$ & $1.21(0.34)$ \\
\hline $\begin{array}{c}\text { Prefrontal } \\
\text { cortex }\end{array}$ & $0.28(0.11)$ & $0.21(0.08)$ & $0.35(0.18)$ \\
\hline $\begin{array}{c}\text { Temporal } \\
\text { cortex }\end{array}$ & $0.37(0.10)$ & $0.29(0.09)$ & $0.40(0.11)$ \\
\hline
\end{tabular}




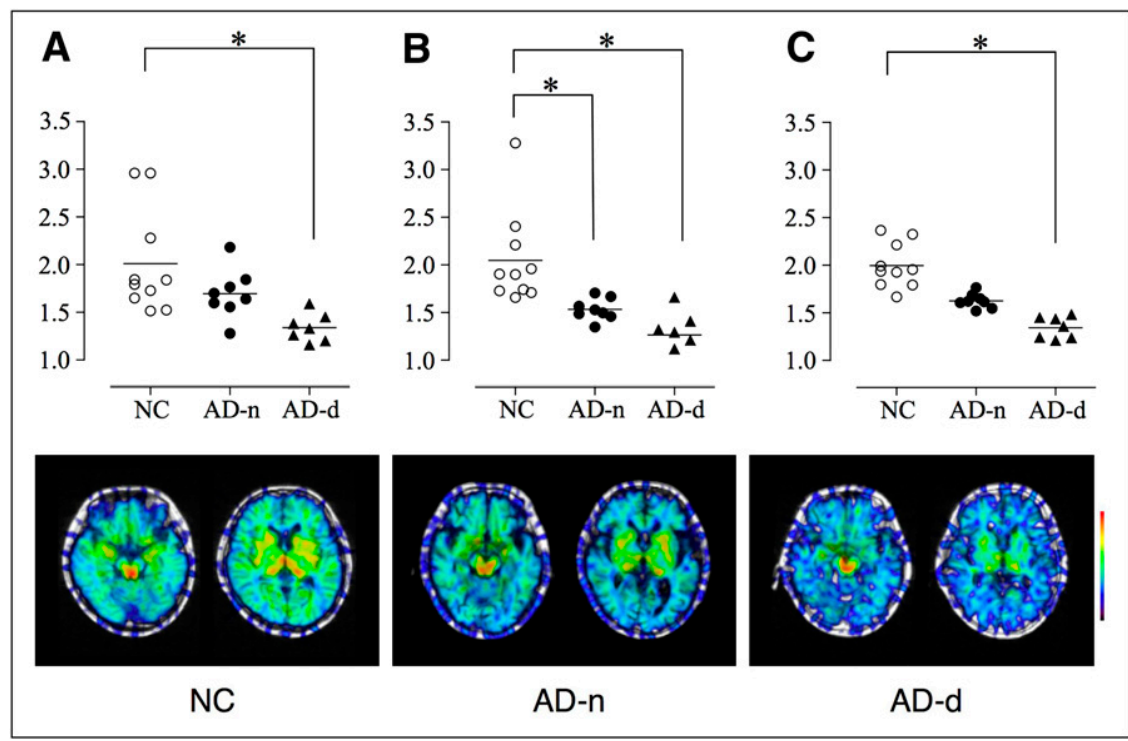

FIGURE 1. Levels of ${ }^{11} \mathrm{C}$-DASB binding within dense $5 \mathrm{HT}$ projection areas in midbrain $(A)$, putamen $(B)$, and thalamus (C). Representative PET images of ${ }^{11} \mathrm{C}$ DASB binding relative to cerebellar uptake are shown. Color scale denotes magnitude of tissue-to-cerebellum ratio, ranging from 0 to 3 . $N C=$ healthy control; $A D-n=$ nondepressive AD; AD$\mathrm{d}=$ depressive AD. ${ }^{*} P<0.05$, ANOVA with post hoc Student-Newman-Keuls test. lated positively with putaminal ${ }^{11} \mathrm{C}$-DASB binding in $\mathrm{AD}$ patients (glass brain: Fig. 3A; Table 3). No other significant correlation was found, but there was a tendency toward a correlation when either ${ }^{11} \mathrm{C}$-DASB BP in the thalamus or $\mathrm{BP}$ in the midbrain was chosen as a covariate (data not shown). The glucose metabolic level in the statistically highest peak region (right DLPFC) statistically correlated negatively with GDS scores in AD patients (Fig. 3B, scattergram, $r=0.798, P<0.0004, \mathrm{f}(\mathrm{x})=-2.34 \mathrm{x}+$ 12.8). Between-group comparison of SPM failed to show any brain region with statistically significant differences in glucose metabolism between the nondepressed and depressed groups (data not shown).

\section{DISCUSSION}

The present results showed a significant reduction in binding of the 5HT transporter marker ${ }^{11} \mathrm{C}$-DASB in subcortical 5HT projection areas (especially the striatum) in patients with early- to moderate-stage $\mathrm{AD}$ regardless of depression and that the reduction was associated with the severity of their depressive states. The brain mapping analysis depicted the right DLPFC as a neural correlate of raphe-striatal 5HT activity in the disease. Furthermore,
DLPFC metabolism was found to correlate with depressive scores, suggesting that $5 \mathrm{HT}$ dysfunction might affect right DLPFC activity, possibly leading to the generation of a clinical phenotype depression in AD. Thus, as suggested ex vivo $(3,28)$, a progressive 5 HT dysfunction may be present in the living brain of patients even in the absence of depression and may worsen the state of emotion.

In the present study, ${ }^{11} \mathrm{C}$-DASB binding in the basal ganglia and thalamus in $\mathrm{AD}$ patients was about $25 \%$ that in healthy subjects-a smaller reduction than the loss of 5HT cell density observed in the raphe nucleus of postmortem AD brains (45\%) (29). Although this difference might be due to differences between antemortem and postmortem specimens, a previous finding that marked 5HT cell attrition occurs regardless of the presence or absence of depression (29) and our finding that striatal ${ }^{11} \mathrm{C}$-DASB binding is reduced in parallel with GDS scores suggest that 5HT neuronal reduction and psychologic deterioration may covary up to the last stage of 5HT neuronal loss in AD patients. Indeed, the 5HT neurons may be affected early in the course of the disease because AD patients with GDS scores of around zero showed a marked reduction in ${ }^{11} \mathrm{C}$-DASB
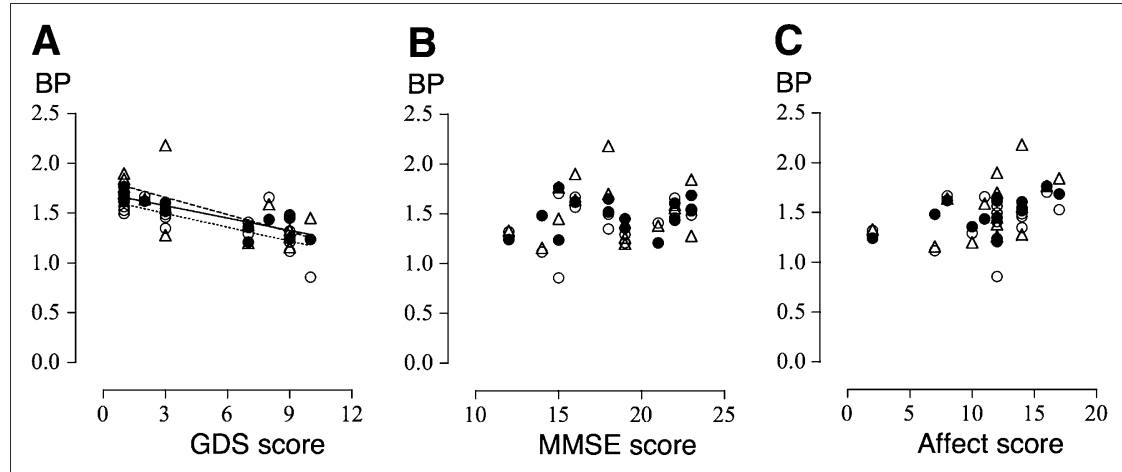

FIGURE 2. Correlations between levels of ${ }^{11} \mathrm{C}$-DASB BP in midbrain $(\triangle)$, putamen $(\bigcirc)$, and thalamus $(\bullet)$ for GDS score (A), Mini-Mental State Examination (MMSE) score (B), and affect score (C) in all AD patients. Dotted (putamen), straight (thalamus), and dashed (midbrain) lines denote significant correlations (Kendall rank correlation, $P<$ 0.01). 
FIGURE 3. SPM images in AD group. (A) SPM correlation analysis showed positive correlation between striatal ${ }^{11} \mathrm{C}$-DASB BP and glucose use in right DLPFC (glass brain, $P<0.001$, uncorrected). (B) SPM responses in area with highest peak (arrow) correlated negatively with GDS scores. Color scale bar denotes $t$ value.

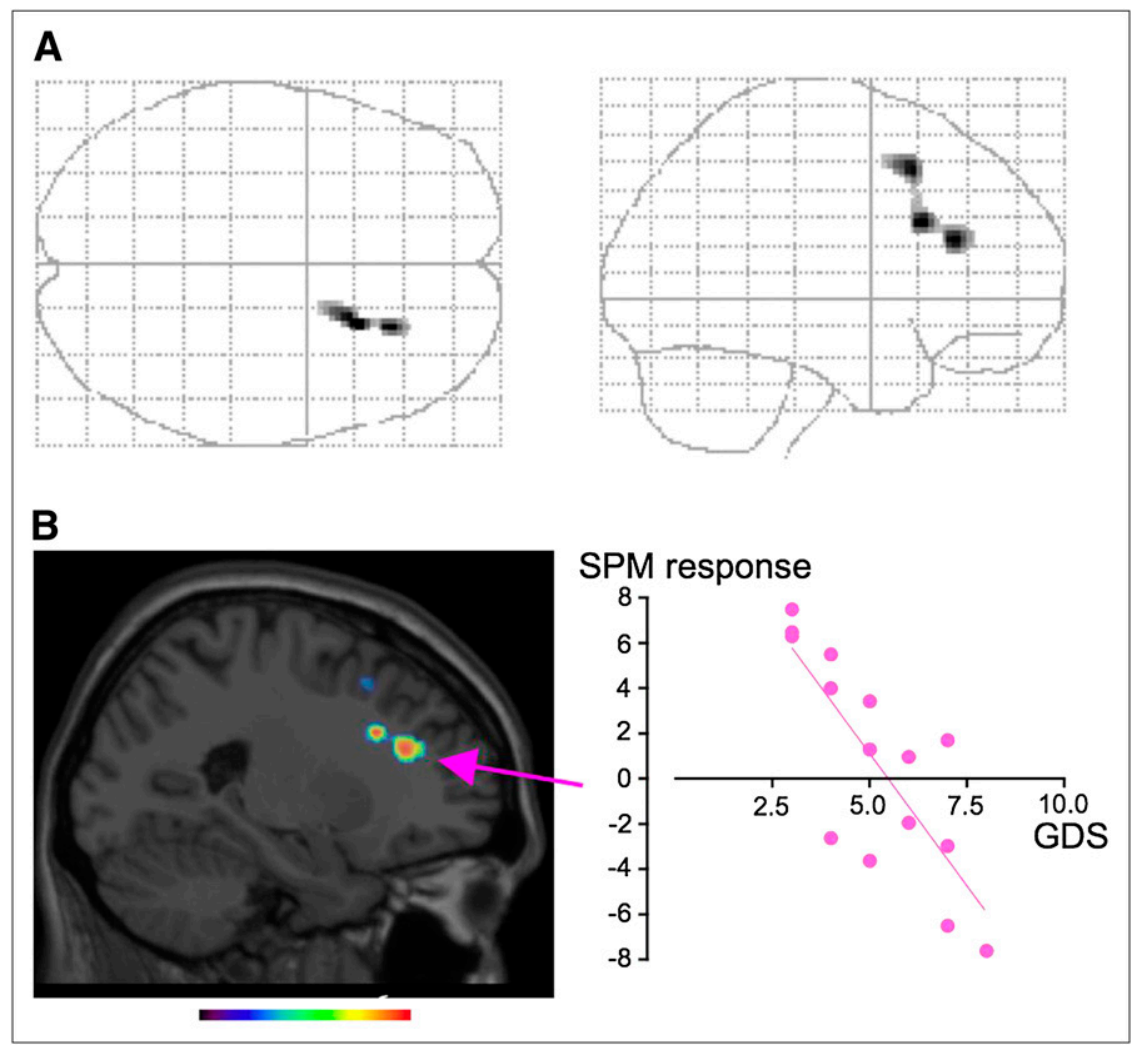

binding specifically in the putamen, compared with that in healthy subjects (Fig. 1B). This finding is in contrast to the increase in binding of $5 \mathrm{HT}$ transporter marker ${ }^{11} \mathrm{C}$ McN5652 in major depression, (30) suggesting that the underlying etiologies are clearly different. The mechanism of 5HT neuronal degeneration in $\mathrm{AD}$ remains unclear, but previous reports about the extent of 5HT neuron loss in the dorsomedial raphe nuclei (28) without association between 5HT transporter polymorphism and depression in depressed AD patients (31) suggest that the 5HT neuronal degeneration seems acquired. This may be true, because aggregation of $\mathrm{A} \beta$ protein exerts an early, focal neurotoxic effect on 5-HT and ACh axons (32).

It was reported that glucose metabolism in the DLPFC was lower in depressed AD patients than in their nondepressed counterparts (33). In the present study, we found a significant correlation between striatal ${ }^{11} \mathrm{C}$-DASB binding and DLPFC glucose metabolism (Fig. 3A), the magnitude of which was associated with the extent of clinical deterioration and depression severity. Although striatal ${ }^{11} \mathrm{C}$ DASB binding was lower in depressed AD patients in the present study, SPM analysis performed separately in each subgroup of $\mathrm{AD}$ (nondepressed and depressed) failed to show statistical significance for any brain region (data not shown). This result may be ascribed to the limited number of patients in each group or the narrow variation in ${ }^{11} \mathrm{C}$ DASB BP in each subgroup. Previous studies showing that the DLPFC was involved in cognitive processing in negative emotion (34) and that successful 5HT augmentation therapy activated prefrontal glucose metabolism (35) would support our finding that striatal 5HT activity is associated with right DLPFC metabolism in AD patients. This right-

TABLE 3. Brain Regions Showing Significant Correlation Between Glucose Metabolism and Striatal ${ }^{11}$ C-DASB

Binding in $A D$

\begin{tabular}{|c|c|c|c|c|c|}
\hline \multirow[b]{2}{*}{ Brain region } & \multirow[b]{2}{*}{ Brodmann area } & \multicolumn{3}{|c|}{ Coordinates } & \multirow[b]{2}{*}{$z$ score } \\
\hline & & $x$ & $y$ & $z$ & \\
\hline \multicolumn{6}{|l|}{ Positive correlation } \\
\hline Right DLPFC & $9 / 46$ & 22 & 22 & 28 & 3.91 \\
\hline Right superior frontal gyrus & 8 & 20 & 16 & 48 & 3.79 \\
\hline \multicolumn{6}{|l|}{ Negative correlation (none) } \\
\hline
\end{tabular}


sided dominancy may reflect a depression-related susceptibility because lesions in the right frontal cortex lead to anxiety and depression (36) and because recent memories preferentially involve the right prefrontal cortex in $\mathrm{AD}$ (37). Thus, there might be a link between this important clinical phenomenon and a 5HT-related alteration in right prefrontal activity.

In the present study, no significant correlation was found between presynaptic 5HT dysfunction and dementia, whereas the scattergrams of Figures $2 \mathrm{~B}$ and $2 \mathrm{C}$ showing a weak tendency toward a correlation may hint that a greater number of patients would exhibit significant correlations in presynaptic 5HT activity and these cognitive abilities. In addition, the limited number of clinical features in $\mathrm{AD}$ in the current study may be responsible for the failure in clinicobiochemical correlation. Previous reports showing that a reduction in 5HT signaling causes synaptic dysfunction and neuronal death in $\mathrm{AD}$ (38) and that enhanced 5HT signaling reduces levels of $A \beta$ protein in the brain of transgenic AD mice (39) would support this speculation. At the moment, however, it is unlikely that the 5HT system is directly involved in the generation of dementia, as opposed to the implications of cholinergic failure in the $\mathrm{AD}$ brain. Because a history of depression is a risk factor of $\mathrm{AD}$, alteration in the 5HT system even at an early stage of the disease should be borne in mind in the management of AD patients. Indeed, in the clinical setting, $\mathrm{AD}$ patients with neuropsychiatric symptoms tend to be institutionalized sooner than those without (40). Thus, on top of anticholinergic and antiamyloid deposition therapy, enhancement of 5HT signaling by, for example, selective 5HT reuptake inhibitors may be important in the treatment and prophylaxis of $\mathrm{AD}$.

\section{CONCLUSION}

This study suggests that a degree of presynaptic 5HT function in the subcortical 5HT projection region is compromised in $\mathrm{AD}$ patients even before the development of depression. Right DLPFC dysfunction in parallel with 5HT inactivation is also implicated in the progression of emotional and cognitive deterioration in $\mathrm{AD}$.

\section{ACKNOWLEDGMENTS}

We thank Dr. Mitsuo Kaneko (Kaneko Clinic), Dr. Masanobu Sakamoto (Hamamatsu Medical Center), Toshihiko Kanno (Hamamatsu Medical Center), and Yutaka Naito (Japan Environment Research Corporation) for their clinical and technical support. This work was supported by a Research Grant for Longevity Science from the Ministry of Health, Labor, and Welfare, Japan.

\section{REFERENCES}

1. Lanctôt KL, Herrmann N, Mazzotta P. Role of serotonin in the behavioral and psychological symptoms of dementia. J Neuropsychiatry Clin Neurosci. 2001; $13: 5-21$.
2. Mann DM, Yates PO. Serotonin nerve cells in Alzheimer's disease [letter]. J Neurol Neurosurg Psychiatry. 1983;46:96.

3. Palmer AM, Francis PT, Benton JS, et al. Presynaptic serotonergic dysfunction in patients with Alzheimer's disease. J Neurochem. 1987;48:8-15.

4. Assal F, Alarcón M, Solomon EC, Masterman D, Geschwind DH, Cummings JL. Association of the serotonin transporter and receptor gene polymorphisms in neuropsychiatric symptoms in Alzheimer disease. Arch Neurol. 2004;61:12491253.

5. Curcio CA, Kemper T. Nucleus raphe dorsalis in dementia of the Alzheimer type: neurofibrillary changes and neuronal packing density. J Neuropathol Exp Neurol. 1984;43:359-368.

6. Zubenko GS, Moossy J, Martinez AJ, et al. Neuropathologic and neurochemical correlates of psychosis in primary dementia. Arch Neurol. 1991;48:619624.

7. Nyth AL, Gottfries CG. The clinical efficacy of citalopram in treatment of emotional disturbances in dementia disorders: a Nordic multicentre study. $\mathrm{Br} \mathrm{J}$ Psychiatry. 1990;157:894-901.

8. Petracca G, Tesón A, Chemerinski E, Leiguarda R, Starkstein SE. A doubleblind placebo-controlled study of clomipramine in depressed patients with Alzheimer's disease. J Neuropsychiatry Clin Neurosci. 1996;8:270-275.

9. Kepe V, Barrio JR, Huang SC, et al. Serotonin 1A receptors in the living brain of Alzheimer's disease patients. Proc Natl Acad Sci USA. 2006;103:702-707.

10. Meltzer CC, Smith G, DeKosky ST, et al. Serotonin in aging, late-life depression, and Alzheimer's disease: the emerging role of functional imaging. Neuropsychopharmacology. 1998;18:407-430.

11. Truchot L, Costes N, Zimmer L, et al. A distinct $\left[{ }^{18} \mathrm{~F}\right] \mathrm{MPPF}$ PET profile in amnestic mild cognitive impairment compared to mild Alzheimer's disease. Neuroimage. 2008;40:1251-1256.

12. Lavoie B, Parent A. Immunohistochemical study of the serotoninergic innervation of the basal ganglia in the squirrel monkey. J Comp Neurol. 1990;299:1-16.

13. Lavoie B, Parent A. Serotoninergic innervation of the thalamus in the primate: an immunohistochemical study. J Comp Neurol. 1991;312:1-18.

14. Thomas AJ, Hendriksen M, Piggott M, et al. A study of the serotonin transporter in the prefrontal cortex in late-life depression and Alzheimer's disease with and without depression. Neuropathol Appl Neurobiol. 2006;32:296-303.

15. Levy-Cooperman N, Burhan AM, Rafi-Tari S, et al. Frontal lobe hypoperfusion and depressive symptoms in Alzheimer disease. $J$ Psychiatry Neurosci. 2008;33:218-226.

16. Davidson RJ, Pizzagalli D, Nitschke JB, Putnam K. Depression: perspectives from affective neuroscience. Annu Rev Psychol. 2002;53:545-574.

17. Mann UM, Mohr E, Chase TN. Rapidly progressive Alzheimer's disease [letter]. Lancet. 1989;2:799.

18. Ouchi Y, Nakayama T, Kanno T, Yoshikawa E, Shinke T, Torizuka T. In vivo presynaptic and postsynaptic striatal dopamine functions in idiopathic normal pressure hydrocephalus. J Cereb Blood Flow Metab. 2007;27:803-810.

19. Weintraub D, Xie S, Karlawish J, Siderowf A. Differences in depression symptoms in patients with Alzheimer's and Parkinson's diseases: evidence from the 15-item Geriatric Depression Scale (GDS-15). Int $J$ Geriatr Psychiatry. 2007;22:1025-1030.

20. Ouchi Y, Yoshikawa E, Okada H, et al. Alterations in binding site density of dopamine transporter in the striatum, orbitofrontal cortex, and amygdala in early Parkinson's disease: compartment analysis for beta-CFT binding with positron emission tomography. Ann Neurol. 1999;45:601-610.

21. Sekine Y, Ouchi Y, Takei N, et al. Brain serotonin transporter density and aggression in abstinent methamphetamine abusers. Arch Gen Psychiatry. 2006;63:90-100.

22. Phelps ME, Huang SC, Hoffman EJ, Selin C, Sokoloff L, Kuhl DE. Tomographic measurement of local cerebral glucose metabolic rate in humans with (F-18)2fluoro-2-deoxy-D-glucose: validation of method. Ann Neurol. 1979;6:371-388.

23. Palacios JM, Waeber C, Hoyer D, Mengod G. Distribution of serotonin receptors. Ann N Y Acad Sci. 1990;600:36-52.

24. Mai JK, Assheuer J, Paxinos G. Atlas of the Human Brain. San Diego, CA: Academic Press; 1997.

25. Logan J, Volkow ND, Fowler JS, et al. Effects of blood flow on $\left[{ }^{11} \mathrm{C}\right]$ raclopride binding in the brain: model simulations and kinetic analysis of PET data. J Cereb Blood Flow Metab. 1994;14:995-1010.

26. Procter AW, Lowe SL, Palmer AM, et al. Topographical distribution of neurochemical changes in Alzheimer's disease. J Neurol Sci. 1988;84:125-140.

27. Ouchi Y, Yoshikawa E, Futatsubashi M, Okada H, Torizuka T, Kaneko M. Activation in the premotor cortex during mental calculation in patients with Alzheimer's disease: relevance of reduction in posterior cingulate metabolism. Neuroimage. 2004;22:155-163.

28. Yamamoto T, Hirano A. Nucleus raphe dorsalis in Alzheimer's disease: neurofibrillary tangles and loss of large neurons. Ann Neurol. 1985;17:573-577. 
29. Hendricksen M, Thomas AJ, Ferrier IN, Ince P, O'Brien JT. Neuropathological study of the dorsal raphe nuclei in late-life depression and Alzheimer's disease with and without depression. Am J Psychiatry. 2004;161:1096-1102.

30. Ichimiya T, Suhara T, Sudo Y, et al. Serotonin transporter binding in patients with mood disorders: a PET study with $\left[{ }^{11} \mathrm{C}\right](+) \mathrm{McN5652}$. Biol Psychiatry. 2002;51:715-722.

31. Li T, Holmes C, Sham PC, et al. Allelic functional variation of serotonin transporter expression is a susceptibility factor for late onset Alzheimer's disease. Neuroreport. 1997;8:683-686.

32. Aucoin JS, Jiang P, Aznavour N, et al. Selective cholinergic denervation, independent from oxidative stress, in a mouse model of Alzheimer's disease. Neuroscience. 2005;132:73-86.

33. Holthoff VA, Beuthien-Baumann B, Kalbe E, et al. Regional cerebral metabolism in early Alzheimer's disease with clinically significant apathy or depression. Biol Psychiatry. 2005;57:412-421.

34. Mayberg HS, Liotti M, Brannan SK, et al. Reciprocal limbic-cortical function and negative mood: converging PET findings in depression and normal sadness. Am J Psychiatry. 1999;156:675-682.
35. Kennedy SH, Evans KR, Krüger $\mathrm{S}$, et al. Changes in regional brain glucose metabolism measured with positron emission tomography after paroxetine treatment of major depression. Am J Psychiatry. 2001;158:899-905.

36. Grafman J, Schwab K, Warden D, Pridgen A, Brown HR, Salazar AM. Frontal lobe injuries, violence, and aggression: a report of the Vietnam Head Injury Study. Neurology. 1996;46:1231-1238.

37. Eustache F, Piolino P, Giffard B, et al. 'In the course of time': a PET study of the cerebral substrates of autobiographical amnesia in Alzheimer's disease. Brain. 2004;127:1549-1560.

38. Mattson MP, Maudsley S, Martin B. BDNF and 5-HT: a dynamic duo in agerelated neuronal plasticity and neurodegenerative disorders. Trends Neurosci. 2004;27:589-594.

39. Nelson RL, Guo Z, Halagappa VM, et al. Prophylactic treatment with paroxetine ameliorates behavioral deficits and retards the development of amyloid and tau pathologies in 3xTgAD mice. Exp Neurol. 2007;205:166-176.

40. Steele C, Rovner B, Chase GA, Folstein M. Psychiatric symptoms and nursing home placement of patients with Alzheimer's disease. Am J Psychiatry. 1990; 147:1049-1051. 